\title{
1980 Annual Conference of the Condensed Matter Division
}

\section{Antwerp}

\section{Date of this Conference is now 9-11 April, 1980}

Summary of the scope of the conference and the programme are as shown on page 12 of the last issue of Europhysics News. Communications should be addressed to :
University of Antwerp (RUCA)

Groenenborgerlaan 171

B - 2020 ANTWERPEN

\section{But How Many Potential Candidates Know}

that the EPS Scholarship Scheme offers a unique opportunity for research both before and after Ph.D. in a new country?

For 1979-80 already, institutes in the Federal Republic of Germany, Italy, Poland, Romania and Switzerland made a total of over 30 Scholarships available. For the next year, EPS expects that an even greater number will come within the scope of the Scheme.

Overleaf details are given of the opportunities at the University of $\mathrm{Nij}$ megen and EPS has just been informed of a new group of four Scholarships in The Netherlands offered by FOM, the Stichting voor Fundamenteel Onderzoek der Materie. The Scholarships are available for Ph.D.s or physicists with special skills, at the institutions shown in the accompanying box. Salary or stipend will be paid by FOM according to experience, responsibilities and costs and will lie in the bracket of 2000-5000 h.FI. per month.

Further information on these and other EPS Scholarships as they are confirmed will be published in subsequent issues of Europhysics News.

Scholarships (not all of which are tied to the academic year) are open to all young physicists whose nationality is that of a country which has a national society that is a member of EPS; young means that a Ph.D. has not been obtained more than five years before.

Early application is strongly recommended - even before exact details have been published - to give maximum time for a dialogue between candidate and host institute, for the refereeing bodies to do their work and for any civil procedures to be completed. Moreover, this is a dynamic situation in which the opportunities can be influenced by the demand.

Now that the new term has started, research supervisory staff are urged to bring the attention of their charges to the existence of the EPS Scholarship Scheme and encourage them to think ahead to 1980-81.

Leaflets (in English) giving more details of the Scheme can be obtained from the Secretariat of EPS but why not a notice on the board of the physics dept. or lab. in the local language? It need not be elaborate.

\section{Europhysics Style Manual}

The reference to the SUN document given in Appendix A of the Style Manual published in the last issue of Europhysics News should be up-dated to the latest edition, the reference of which is: Document UIP 20 (1978). The address showing where it may be obtained is unchanged.

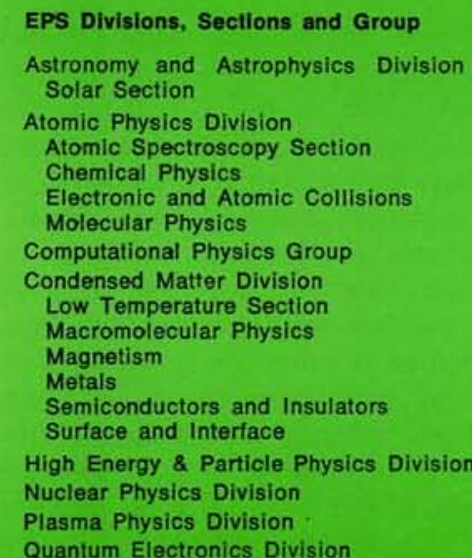

Europhysics News is the official journal of the European Physical Society that comprises $28 \mathrm{Na}$ tional Societies. Academies and Groups, over 3000 Individual Ordinary Members and 30 Associate Members. Governing bodies of EPS are the General Meeting. Council and an elected Executive Committee responsible for detalled policy. Utive promotes the collaboration of physicists international exchange in physics. EPS awards scholarships for research and studies in different countries. EPS publishes, in addition to Europhyslcs News, Europhysics Conference Abstracts, Eulcs News, EvS publics in addition to Euraphys- Europhysics Education News and the Proceedings of its General Conferences. Individual Ordinary Members receive Europhysics News (subscription for non-Members: $75 \mathrm{Sw}$. Fr.Ja), substantial rebates on many publications and pay reduced fees at conferences. Application for membership is made through the permanent Secretariat in Geneva. Annual subscription for members of a National Society from 1 January, 1980 is 32 Sw.Fr. EPS promotes the collaboration of physicists

\section{FOM Institutes} Open to EPS Scholarships

- The FOM-Institute for Atomic and Molecular Physics at Amsterdam: beams, spectroscopy, semiconductors, surface physics, plasma physics, flash pyrolysis.

- Nuclear Physics Accelerator Institute, KVI, at Groningen: large variable energy cyclotron, light and heavy ions, multi nuclear transfer reactions, giant resonances, continuum gamma rays, projectile break-up and incomplete fusion, theoretical nuclear physics.

- National High Physics Institute, NIKHEF/H, at Amsterdam: experimental programme based on CERN and other accelerator laboratories, counter techniques and bubble chambers, small theory group.

- Department of High Energy Physics, University of Nijmegen: ibid, development for automatic measurements for particle physics and cancer research.

- Huygens Laboratory, University of Leiden: non-spherical molecules, beams, transport properties, nonequilibrium studies.

\section{National Society}

The new President of the Norwegian Physical Society is Dr. Eivind Osnes, of the University of Oslo. 